\title{
Regulation of transcription of the RNA splicing factor hSlu7 by Elk-1 and Sp1 affects alternative splicing
}

\author{
MOTI ALBERSTEIN, ${ }^{1,4}$ MAAYAN AMIT, ${ }^{1,4}$ KEREN VAKNIN, ${ }^{1}$ AMANDA O'DONNELL, ${ }^{2}$ CHEN FARHY, ${ }^{1}$ \\ YANIV LERENTHAL, ${ }^{1}$ NOAM SHOMRON, ${ }^{3}$ OHAD SHAHAM, ${ }^{1}$ ANDREW D. SHARROCKS, ${ }^{2}$ \\ RUTH ASHERY-PADAN, ${ }^{1}$ and GIL AST ${ }^{1}$ \\ ${ }^{1}$ Department of Human Molecular Genetics and Biochemistry, Sackler Faculty of Medicine, Tel-Aviv University, Tel Aviv 69978, Israel \\ ${ }^{2}$ Faculty of Life Sciences, University of Manchester, Manchester M13 9PT, United Kingdom \\ ${ }^{3}$ Department of Biology, Massachusetts Institute of Technology, Cambridge, Massachusetts 02139, USA
}

\begin{abstract}
Alternative splicing plays a major role in transcriptome diversity and plasticity, but it is largely unknown how tissue-specific and embryogenesis-specific alternative splicing is regulated. The highly conserved splicing factor Slu7 is involved in $3^{\prime}$ splice site selection and also regulates alternative splicing. We show that Slu 7 has a unique spatial pattern of expression among human and mouse embryonic and adult tissues. We identified several functional Ets binding sites and GC-boxes in the human Slu7 (hSlu7) promoter region. The Ets and GC-box binding transcription factors, Elk-1 and Sp1, respectively, exerted opposite effects on hSlu7 transcription: Sp1 protein enhances and Elk-1 protein represses transcription in a dose-dependent manner. Sp1 protein bound to the hSlu7 promoter in vivo, and depletion of Sp1 by RNA interference (RNAi) repressed $h S l u 7$ expression. Elk-1 protein bound to the hSlu7 promoter in vivo, and depletion of Elk-1 by RNAi caused an increase in the endogenous level of $h S l u 7$ mRNA. Further, depletion of either Sp1 or Elk-1 affected alternative splicing. Our results provide indications of a complex transcription regulation mechanism that controls the spatial and temporal expression of Slu7, presumably allowing regulation of tissue-specific alternative splicing events.
\end{abstract}

Keywords: Slu7; alternative splicing; spliceosome; Elk-1; Sp1; transcription

\section{INTRODUCTION}

Human and mouse possess a similar number of proteincoding genes $(\sim 24,000)$ (Lander et al. 2001; Waterston et al. 2002). Current estimates indicate that the total number of human proteins exceeds the number of genes. Research is therefore needed to determine the mechanisms that underlie this discrepancy. Alternative splicing is known to significantly expand the transcriptomic potential and genetic diversity (Graveley 2001; Ast 2004; Xing and Lee 2006). Alternative splicing varies among tissues (Hanamura et al. 1998; Yeo et al. 2004; Ule et al. 2005), either as a function of different developmental stages (Wang and Grabowski 1996; Cooper 2005) or due to different physiological conditions (van der Houven van Oordt et al. 2000; Pelisch et al. 2005;

\footnotetext{
${ }^{4}$ These authors contributed equally to this work.

Reprint requests to: Gil Ast, Department of Human Molecular Genetics and Biochemistry, Sackler Faculty of Medicine, Tel-Aviv University, Tel Aviv 69978, Israel; e-mail: gilast@post.tau.ac.il; fax: +972-3-640-9900.

Article published online ahead of print. Article and publication date are at http://www.rnajournal.org/cgi/doi/10.1261/rna.492907.
}

Shomron et al. 2005; Guil et al. 2006). There is also a link between aberrant splicing and human diseases, including cancer (Philips and Cooper 2000; Zhang et al. 2006).

Splicing is a highly conserved process from yeast to human, in which introns are removed from mRNA precursor and exons are ligated to generate mature mRNA. Four short sequences direct the splicing machinery to the splice junctions: the $5^{\prime}$ and $3^{\prime}$ splice sites ( $5^{\prime}$ ss and $3^{\prime}$ ss), the branch-site (BS) sequence, and the polypyrimidine tract; the latter two regions are located upstream of the 3 'ss. The splicing reaction consists of two consecutive catalytic steps and is facilitated by a dynamic protein-RNA complex, known as the spliceosome. The spliceosome is composed of five small nuclear ribonucleoprotein particles (U1, U2, U4, U5, and U6 snRNPs) and more than 150 proteins (Black 2003).

The splicing factor $S l u 7$ was originally identified in yeast as a ubiquitous protein that was found to be synthetically lethal with U5. It is involved in the second step of splicing and is dispensable for in vitro splicing of introns with less than 12 nucleotides (nt) between the BS and the 3'ss (Frank et al. 1992; Zhang and Schwer 1997). 
In vitro, the human ortholog (hSlu7) affects the fidelity of $3^{\prime}$ ss selection when an incorrect 3 'ss sequence is adjacent to the functionally correct site. In the absence of $h S l u 7$ the incorrect 3 'ss is activated. This activation only occurs when the distance between the $3^{\prime}$ ss and the BS is not more than $\sim 30$ nt (Chua and Reed 1999b). Recently, hSlu7 was shown to regulate alternative splicing by a sensitive nucleo-cytoplasmic shuttling. This shuttling controls the nuclear concentration of hSlu7 following specific physiologic stress conditions (Lev-Maor et al. 2003; Shomron et al. 2004, 2005).

Although the conservation of $h S l u 7$ from yeast to human suggests that it is a ubiquitous spliceosomal protein, we demonstrated that $h S l u 7$ is not required for cell viability in the examined cell lines (Shomron et al. 2005). This observation raises the question of whether Slu7 is indeed a constitutively expressed protein. Here, we show that the mammalian SluT is differentially expressed in various tissues and cell lines and also in developing embryonic tissues. We have begun to unravel the elaborate regulatory mechanism of $h S l u 7$ transcription. A complex promoter arrangement that controls hSlu7 temporal and spatial expression via several potential Ets-like transcription factor binding sites (also called EBS) was identified. Some of these sites function as positive and others as negative regulatory elements. Also, two functional regions rich in GC-boxes that may be recognized by the zinc finger transcription factor Sp1 were identified. The experiments described suggest that $\mathrm{Sp} 1$ protein elevates transcription of $h S l u 7$, whereas Elk-1, a member of the ETS transcription factor family, represses hSlu7 transcription. Both Sp1 and Elk-1 proteins bound the hSlu7 promoter in vivo. Consistent with a repressive role, depletion of Elk-1 in HeLa cells induced hSlu7 endogenous expression. In contrast, depletion of Spl repressed $h S l u 7$ expression. Silencing of Elk-1 or Sp1 proteins affected alternative splicing of specific exons. The expression pattern of Slu7 appears to be controlled by a complex promoter arrangement and is activated or repressed by specific regulatory genes. Our data imply that Slu7 is a splicing factor that regulates tissue- and embryonic-specific alternative splicing events.

\section{RESULTS}

\section{Slu 7 is differentially expressed in tissues and cell lines}

We have shown previously that $h \operatorname{Slu} 7$ is not required for cell survival (Shomron et al. 2005). This observation raised the question of whether Slu7 was expressed ubiquitously in all tissues and conditions. Thus, we analyzed Slut protein and mRNA expression within various tissues and cell lines (Fig. 1). High levels of hSlu7 protein were detected in 293T (human kidney embryonic cells), HepG2 (liver carcinoma), and Du145 (prostate carcinoma brain metastasis) cell lines (Fig. 1A, lanes 1-3). Low protein levels were detected in PC3 (prostate adenocarcinoma) and HT1080 (fibrosarcoma) cells (Fig. 1A, lanes 4,5). The mRNA level of $h S l u 7$ is correlated with that of the protein: high levels of both the protein and mRNA in Du145 cells and very low levels in PC3 cells (Fig. 1A, lanes 6,7). Slu7 transcripts were also differentially expressed in various healthy adult tissues in both human and mouse (data not shown).

We then characterized mouse Slu7 (mSlu7) transcript distribution within complex adult tissues from mouse. Paraffin sections of adult mouse pancreas and eye (postnatal days 30 and 15) were hybridized with a specific RNA probe against $m S l u 7$ mRNA (see Materials and Methods). A unique pattern of expression of mSlu7 within the pancreas and neuroretina was observed. In the pancreas, $m S l u 7$ transcripts were detected in the islets of Langerhans, but not in the acinar exocrine cells (Fig. 1B, panel 1). In the

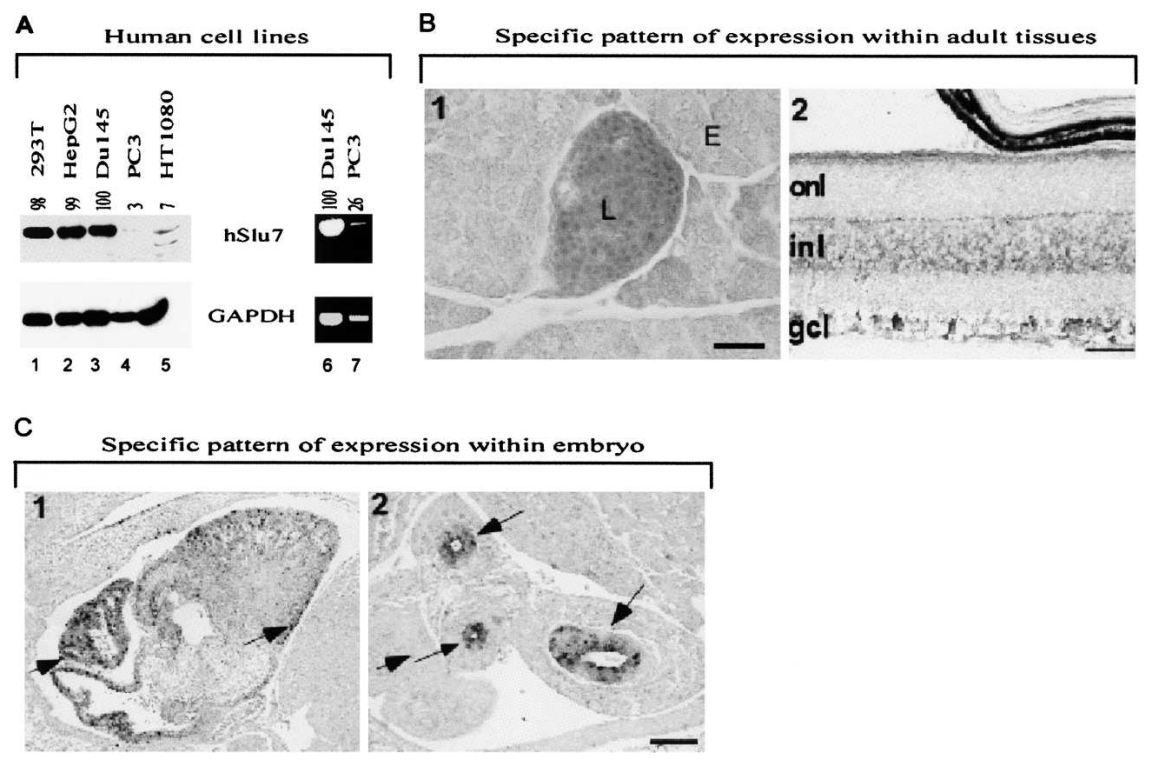

FIGURE 1. Evidence for differential expression of the mammalian Slu7. mRNA and protein levels of human and mouse Slu7 ( $h S l u 7$ and $m S l u 7$, respectively) were analyzed in adult and embryonic tissues and cell lines. (A) Protein and mRNA levels in different human cell-line lysates were analyzed by Western blot using an anti-Slu7 antibody (lanes 1-5) or RT-PCR (lanes 6,7). (B) In situ hybridization using an $m S l u 7$ antisense probe was performed on paraffin sections of pancreas and eye from postnatal day 30 (P30) and day 15 mice (P15), respectively. The expression of $m S l u 7$ in the adult pancreas is detected in the islets of Langerhans (L) but not in the exocrine (E) tissue (panel B1). In the eye $m S l u 7$ transcript was detected in the neuroretina (panel B2). (gcl) Ganglion cell layer; (inl) inner nuclear layer; (onl) outer nuclear layer. Scale bar, $100 \mu \mathrm{m}$. (C) In E12.5 embryo the expression of $m S l u 7$ is detected in the developing heart (panel C1) and in the epithelium of the developing lung buds (arrow heads) but not in the surrounding mesenchyme (panel C2). Regions of high mSlu7 expression are marked by arrow heads. Scale bar, $50 \mu \mathrm{m}$. 
neuroretina, $m S l u 7$ was abundant in the inner nuclear layer and the ganglion cell layer but was weakly expressed in the outer nuclear layer (Fig. 1B, panel 2) and the cornea (data not shown). Furthermore, differential tissue expression was observed in mouse embryo; mSlu7 transcripts were abundant in the developing heart and in the epithelium of the lung buds but not in the surrounding mesenchyme (Fig. $1 \mathrm{C}$, panels 1 and 2, respectively). These results demonstrate that Slu7 is expressed differentially among tissues and during development, thus implicating $S l u 7$ as a contextdependent modulator of the splicing machinery.

\section{Cloning and analysis of the hSlu7 promoter structure}

The observation that mammalian Slu7 was expressed differentially led us to question its transcription regulation. A rapid amplification of $5^{\prime}$ cDNA ends (5'-RACE) analysis was used to identify the transcription start sites (TSSs) of the human Slu7 gene (see Supplemental Material). Four alternative TSSs were identified; the most abundant was selected in 11 of the 20 clones sequenced (see Fig. 2A; Supplemental Material). The most prevalent TSS was chosen as the reference point for the reporter construct assay and was named TSS(1). It is important to note that the use of a different TSSs does not affect the coding sequence but rather changes the length of the $5^{\prime}$ UTR. We then cloned the human Slu7 promoter from position -184 upstream to position +66 base pairs (bp) downstream from TSS(1) into firefly luciferase reporter plasmid (Fig. 2B). Comparative analysis of the $S l u 7$ promoter region (covering the first exon and 184 bp upstream) from a variety of mammals revealed $100 \%$ conservation of the TSS(1) region (Fig. 2C, marked by an arrow), which implies that this region is significant, probably for recruitment of basal transcription machinery.

We analyzed the construct for promoter activity and found it to be transcriptionally active by more than $10^{3}$ fold above the empty control pGL3 vector background signal (data not shown). Next, we searched for putative trans-acting factor binding sites, using several computational programs (see Materials and Methods). We also examined the conservation level within the promoter region using multispecies comparative analysis (Fig. 2C). Using this analysis, two types of putative transcriptional binding sites were identified. The first to be identified were two promoter regions rich in GC that contain potential binding sites for the transcription factor $S p 1$ (Fig. 2C). We also identified five tandem putative Ets binding sites (marked $\mathrm{EBS}_{\mathrm{a}-\mathrm{e}}$ ) with a core sequence of GGAA (Fig. 2C; notice that $\mathrm{EBS}_{\mathrm{e}}$ is in the reverse orientation). The Ets family of transcription factors binds to a consensus sequence CCGGAA. Only EBS ${ }_{\mathrm{a}}$ and $\mathrm{EBS}_{\mathrm{c}}$ fully matched the conserved sequence in all mammals tested, whereas $E S_{d}$ and $E B S_{e}$ are primate specific. The Ets family of transcription factors consists of several members that are expressed in a tissue- and a cell-type-specific manner (Sharrocks 2001; Hsu et al. 2004).

\section{hSlu7 promoter activity is regulated by EBS elements}

To examine the functionality of the putative EBS elements, we generated specific point mutations within the GGAA elements (the mutations are shown in Fig. 2B). 239T cells were transfected with either the pSlu7-luc reporter construct or the mutant reporter constructs, and cell lysates were tested for luciferase activity $48 \mathrm{~h}$ post-transfection. Activities of the mutant reporter constructs were normalized with respect to the wild-type (WT) pSlu7-luc reporter activity, and results are shown as fold induction (Fig. 2D). Point mutations within the core GGAA elements revealed that all of the five elements were required for the normal transcriptional activity of $h S l u 7$, and each of the elements uniquely regulates $h S l u 7$ transcription in $293 \mathrm{~T}$ cells. Three of the EBS elements, $\mathrm{EBS}_{\mathrm{a}}, \mathrm{EBS}_{\mathfrak{c}}$, and $\mathrm{EBS}_{\mathrm{e}}$, functioned as positive regulatory elements, because mutations of these elements resulted in $40 \%, 50 \%$, and $75 \%$ reduction in WT activity, respectively (Fig. 2D, a,c,e). The other two EBS sites, $\mathrm{EBS}_{\mathrm{b}}$ and $\mathrm{EBS}_{\mathrm{d}}$, functioned as repressive elements; mutations in these elements resulted in $>2.5$ - and $>1$.4-fold induction in the transcriptional activity, respectively (Fig. $2 \mathrm{D}, \mathrm{b}, \mathrm{d})$. It is notable that two of the functional elements, $E_{\mathrm{d}}$ and $\mathrm{EBS}_{\mathrm{e}}$, are primate specific (Fig. 2C).

Double and triple mutants revealed a compensatory relationship between the EBS sites. For example, a point mutation in the core GGAA of the highly conserved enhancer $\mathrm{EBS}_{\mathrm{a}}$ abolished the effect of mutations in either one or both of the repressors $\mathrm{EBS}_{\mathrm{b}}$ and $\mathrm{EBS}_{\mathrm{d}}$ (Fig. 2D, $\mathrm{ab}, \mathrm{ad}, \mathrm{abd})$. Induction of the activity by mutations that abolished the repression by $\mathrm{EBS}_{\mathrm{b}}$ or $\mathrm{EBS}_{\mathrm{d}}$ was partially reduced when combined with a mutation in the enhancer element $\mathrm{EBS}_{\mathrm{c}}$ (Fig. 2D, bc,cd). Finally, deletions within the two potential Sp1 sites, GC-rich1 and GC-rich2, resulted in moderate effects of $+20 \%$ and $-20 \%$, respectively, on the promoter activity (Fig. 2D, GC-1 Del and GC-2 Del). However, deletions in both regions resulted in more than $40 \%$ reduction in basal activity (Fig. 2D, GC-12 Del) implying an important role of these regions in mediating Sp1 induction. The mutational analyses provide evidence for the functionality of all five EBS elements and each of the two GC-rich elements in both up- and down-regulation of the $h S l u 7$ promoter activity.

\section{hSlu7 promoter activity is up-regulated by Sp1 in vivo}

We next asked whether specific transcription factors can regulate $h S l u 7$ expression in vivo. Thus, $293 \mathrm{~T}$ cells were cotransfected with the pSlu7-luc reporter construct and with increasing amounts $(0.25,0.5$, and $0.75 \mu \mathrm{g})$ of a vector expressing Sp1 protein (pcDNA4-Sp1; Fig. 3A), a vector expressing Elk-1 protein (pCAG-Elk-1; Fig. 4A,B), or the 
A

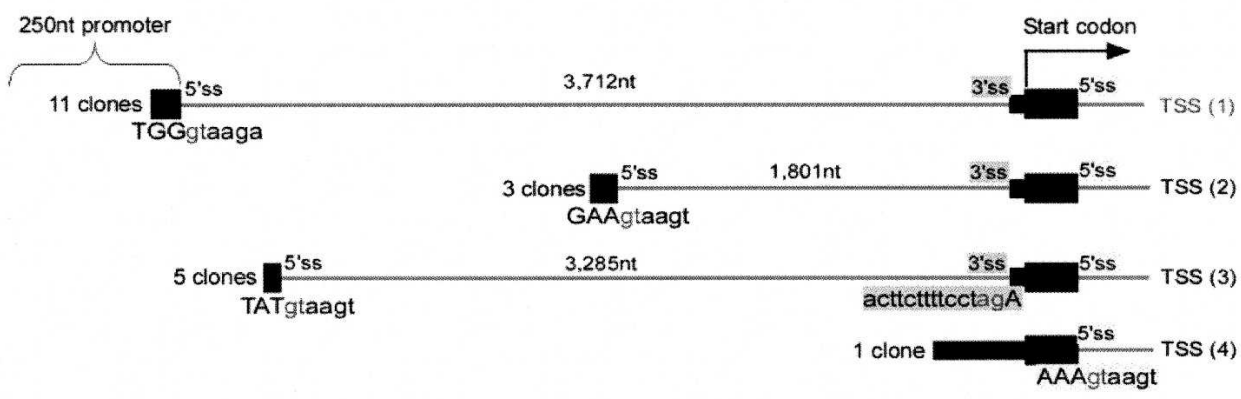

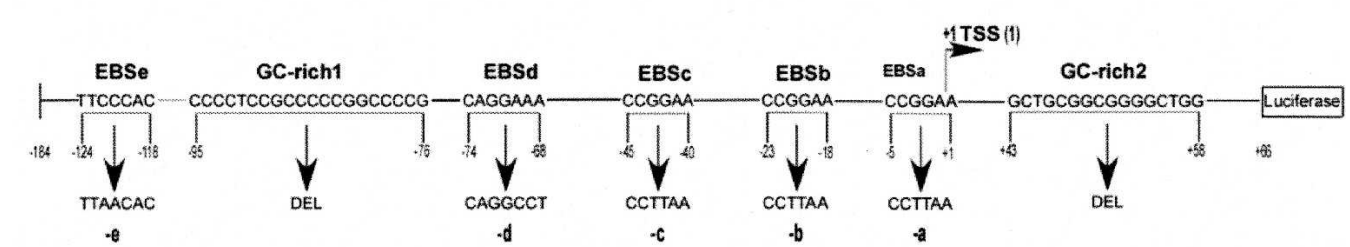

C

$\mathbf{E B S}_{\mathrm{e}}$

GC-rich1

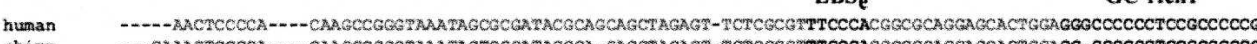

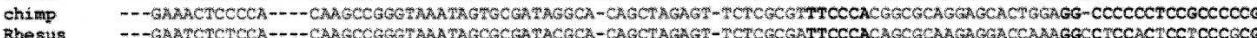

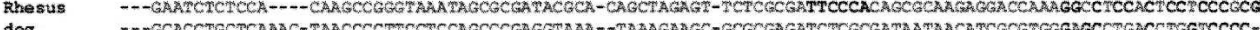

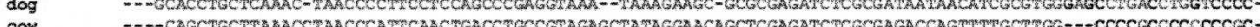
cow rat Armadill

EBS $_{\mathbf{a}}$

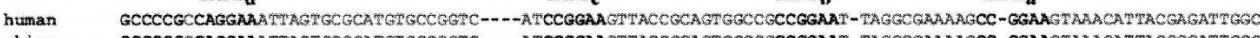

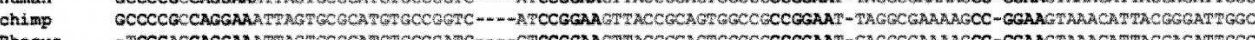

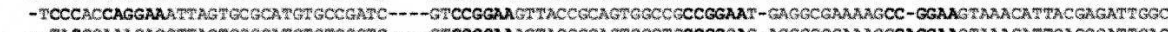

cow

mat

Anaditio

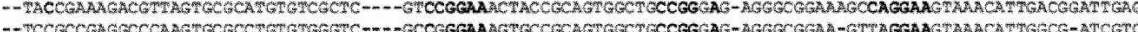

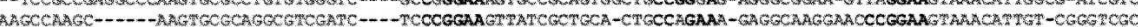

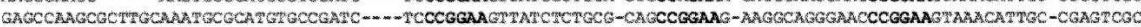

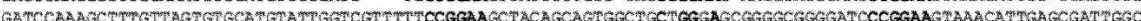

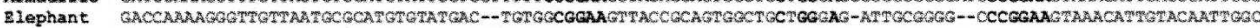

\section{C-rich 2}

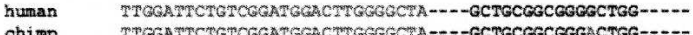

chimp TTGEATRCTGTOGEATEGACTHGCGGCTA----GCTGCGGCGGGACTGG---.-

Rhesus TrG----nCTCGGATGCACTRTACACCA----GCTGCGGCGGACTGGGTAAS

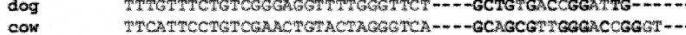

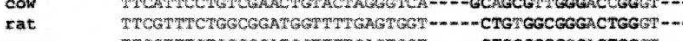

mouse TrCOTTWCTGGCGGATGGXTYTHGAGTGG-----CTGCGGCGCGACTGGGT-

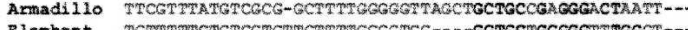

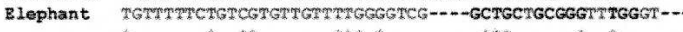

D

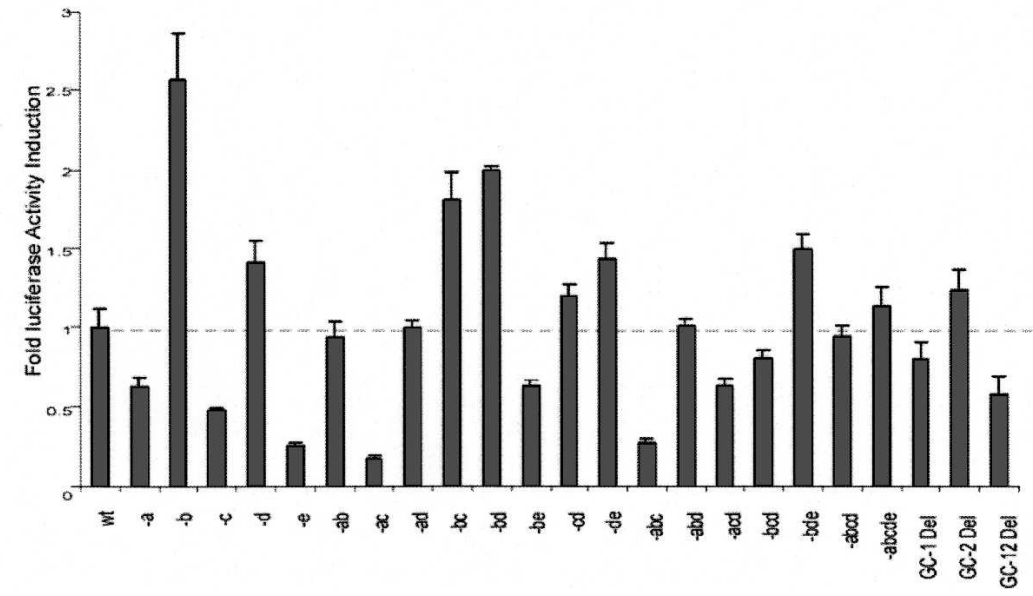

FIGURE 2. (Legend on next page) 
relevant empty control vectors (pcDNA4 and pCAGGS, respectively). Cells were harvested $48 \mathrm{~h}$ post-transfection and cell lysates were tested for luciferase activity (Figs. 3A, $4 A, B)$. Luciferase reporter activities were measured and normalized to the relevant empty control vectors (WT activities). All activities were also normalized to an internal control construct to normalize for transfection efficiency (see Materials and Methods). Cotransfection of Sp1 and pSlu7-luc vectors revealed specific and dose-dependent regulation of the $h S l u 7$ promoter activity, with $\sim 1.5$-fold induction at the highest dose (Fig. 3A, left panel). This induction was also observed in two other cell lines, HT1080 fibrosarcoma and U2OS osteosarcoma cells (data not shown). Deletions of either of the GC-rich elements (GCrich1 or GC-rich2) did not abolish the Sp1-mediated activation of the hSlu7 promoter. However, deletions in both regions significantly reduced Sp1-mediated induction from about twofold to about 1.3-fold (Fig. 3A, right panel; GC-12 Del-luc represent deletions in both GC-rich1 and GC-rich2). This suggests that these regions have important, but compensatory, functions in Sp1-mediated activation of $h S l u 7$ transcription. The moderate induction by $\mathrm{Sp} 1$ may be explained by the fact that the GC-rich regions serve as targets for many other transcription factors that might play a role in of $h S l u 7$ transcription. These results highlight the complexities of regulation of this promoter.

We also demonstrated that $S p 1$ binds to $h S l u 7$ promoter in vivo. U2OS cells were transfected with HA-Sp1 (in pcDNA4) using an empty pCDNA4 as a control, and cells were grown for $48 \mathrm{~h}$. Chromatin immunoprecipitation (ChIP) was then performed using two sets of primers. The first targeted the $h S l u 7$ promoter $(-140$ to +44 , relative to TSS(1); see Materials and Methods) and the second hSlu7 intronic sequence (Fig. 3B, left panel intron 6, +6804 to +7002). The primers were designed to detect specific chromatin fragments immunoprecipitated by either hemagglutinin (HA) or nonspecific IgG antibodies (Fig. 3B, right panel). A specific and intense signal from the $h S l u 7$ promoter region was detected by PCR after immunoprecipitation with the HA antibody but not with nonspecific antibodies (Fig. 3B, right panel, cf. upper and lower panels). This result showed that Sp1 binds the hSlu7 promoter in vivo.

Furthermore, in situ hybridization analysis revealed that Sp1 and Slu7 were expressed in partially overlapping patterns in the mouse eye at postnatal day 15 (P15) within specific layers of the retina and cornea (data not shown). Altogether our results support the hypothesis that Slu7 transcription is regulated by the zinc finger transcription factor Sp1.

\section{Elk-1 binds to the $h S l u 7$ promoter in vivo and represses $h \mathrm{Slu} 7$ expression}

We then looked for a transcription factor that could serve as cellular guard that represses $h S l u 7$ expression. We found that Elk-1 down-regulates $h S l u 7$ promoter activity more than $90 \%$ in a dose-dependent manner (Fig. 4A). Another Ets transcription factor, $E R F$, which is known to have a strong transcriptional repressor activity (Sgouras et al. 1995), did not affect $h S l u 7$ promoter activity (not shown). This suggests that the repression activity mediated by Elk-1 is specific within the Ets family. The repression of hSlu7 transcription by Elk-1 is presumably a general effect, as this repression was observed in all of the investigated cell lines with only minor differences (Fig. 4B). Also, repression was observed even at very low levels of transfected plasmid (50 ng), implying high sensitivity of Elk-1 to $h S l u 7$ promoter.

To validate the regulatory effect of Elk- 1 on the $h S l u 7$ promoter, we examined binding of Elk-1 to the hSlu7 promoter in vivo. ChIP assays were performed in HeLa cells using the same set of primers described for analysis of Sp1 binding to detect specific chromatin fragments immunoprecipitated by either Elk-1 antibody or nonspecific antibodies (Fig. 5A). A specific signal from the $h S l u 7$ promoter region was detected by PCR after immunoprecipitation with the Elk-1 antibody but not with nonspecific antibodies (Fig. 5B). This result shows that Elk-1 protein binds to the $h S l u 7$ promoter in vivo.

To further validate this result, Elk-1 expression was reduced by treatment of HeLa cells with a small interfering RNA (siRNA) that targets Elk-1; nontargeting control

FIGURE 2. Comparative genomic and nucleotide sequence analysis of the Slu7 promoter region predicts functional Sp1 and EBS elements within the $h S l u 7$ promoter. (A) Alternative transcription start sites of human Slu7 gene. Four alternative TSSs were identified using a $5^{\prime}$-RACE analysis. Black boxes represent exons and gray lines introns. The 250-nt promoter region is marked on the left with a brace. The distribution of the 20 clones is indicated near each TSS. The genuine start codon of $h S l u 7$ protein is indicated with an arrow. (B) Schematic representation of the cloned $h S l u 7$ promoter fused to a luciferase reporter construct. Seven putative transcription factor binding sites are indicated at the top. Arrows indicate specific mutations at the EBS and Sp1 sites (below). Transcription start site of the most prevalent TSS [TSS(1)] was used as a reference point and is indicated with an arrow. $(C)$ Multiple sequence alignment of the $5^{\prime}$ region (including the first exon) of the Slu 7 gene from several mammalian organisms is shown. Alignments were generated using the ClustalW algorithm (Thompson et al. 1994). Putative Ets $\left(\right.$ GGAA core element; EBS $_{\mathrm{e}}$ is in an inverted orientation) and GC-rich/Sp1 putative binding sites are marked above the alignment. $(D)$ Functionality of the EBS elements and regulation of Slu7 promoter activity. 293T cells were cotransfected with either the wild type (wt) pSlu7-luciferase (pSlu7-luc) reporter plasmid [containing the -184 to +66 promoter region, with respect to TSS(1)] or various mutant reporter constructs containing single point mutations or combinational point mutants in the core GGAA elements (see also Materials and Methods) or deletions in the GC-rich sites (panel $B$ shows the mutations). Relative luciferase activity was examined $48 \mathrm{~h}$ post-transfection and normalized to the wt promoter activity (shown by a broken line). All results are represented as the mean of at least three independent experiments (standard error bars are shown; $n=3$ ). 


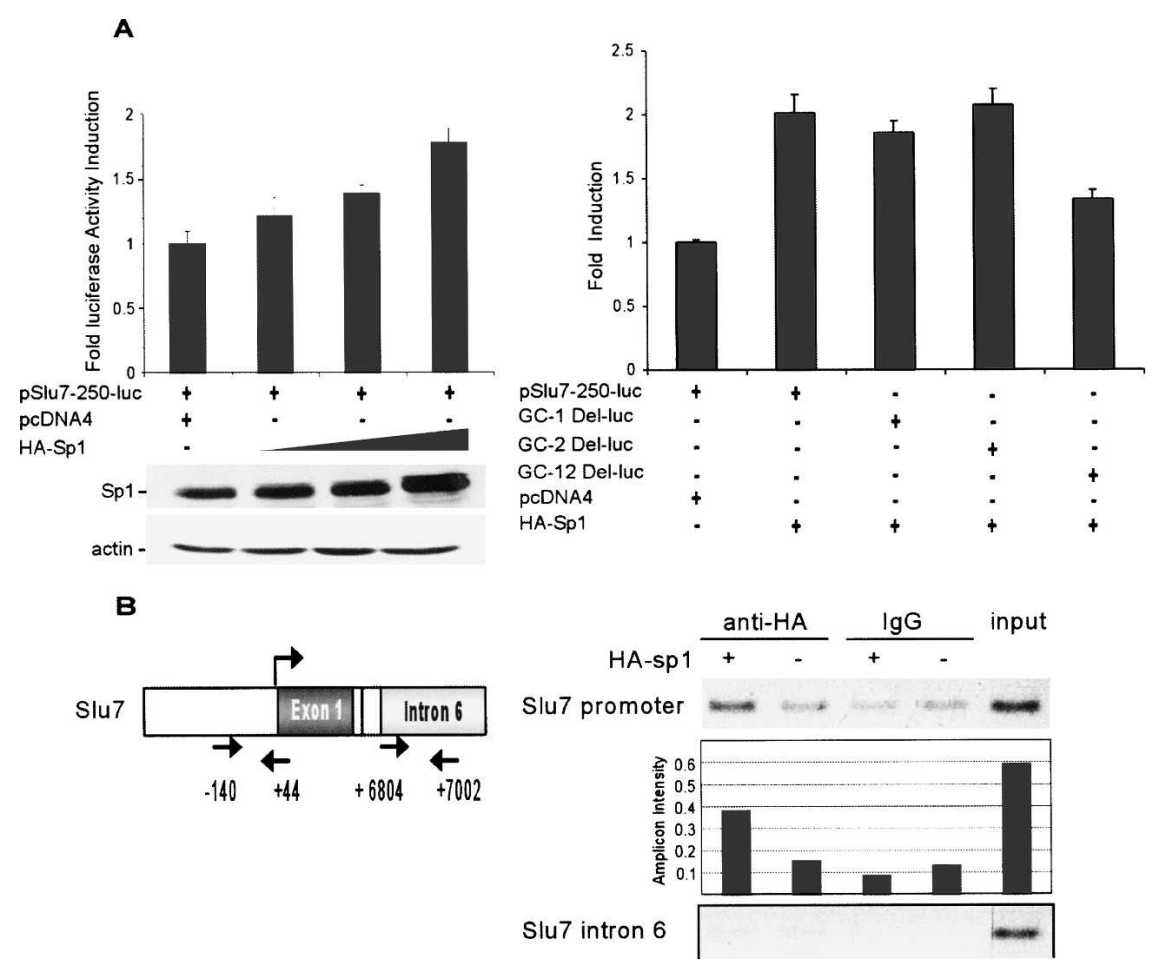

FIGURE 3. Sp1 up regulates $h S l u 7$ promoter activity with $750 \mathrm{ng}$ of pcDNA4-Sp1. (A, left panel) Induction of $h S l u 7$ promoter activity by Sp1. 293T cells were cotransfected with $250 \mathrm{ng}$ of reporter construct (pSlu7-luc) together with $250 \mathrm{ng}$, $500 \mathrm{ng}$, or $750 \mathrm{ng}$ of either the expression plasmid pcDNA4-Sp1 or the corresponding pcDNA4 empty control vector. The fold induction represents the fold increase in luciferase activity $48 \mathrm{~h}$ post-transfection relative to that obtained following cotransfection of the reporter construct with control vector (pCDNA4). (Lower panel) Western blotting of 293T transfected cells with either anti-Sp1 or anti-actin antibodies. (Right panel) Spl mediated induction is significantly impaired only after deletion of the two GC-rich regions. Similar analysis as showed in the left panel using mutants with deletion of GC-rich1 or -2 (GC-1 Del-luc and GC-2 Del luc, respectively) or deletions of both GC-rich regions (GC-12 Del-luc) (see also Fig. 2B) with 750 ng of pcDNA4-Sp1. All luciferase activities are normalized to the wt activity (reporter and empty pcDNA4 vector). Results are represented as the mean of at least three independent experiments (standard errors bars are shown; $n=3$; $P$-values represent $T$-test for each DNA dose group; 0.046, 0.020, and 0.007 for $250 \mathrm{ng}, 500 \mathrm{ng}$, and $750 \mathrm{ng}$, respectively). (B) Sp1 binds to the Slu7 promoter in vivo. Schematic diagram of the Slu7 gene showing the location of the oligonucleotides used in the chromatin immunoprecipitation assay (left panel). U2OS cells were transfected with HA-Sp1 and an empty pCDNA4 and grown for $48 \mathrm{~h}$. Chromatin was precipitated using anti-HA or normal mouse IgG antibodies and used as a template for PCR analysis using primers spanning the promoter region of $h S l u 7$ (right panel; upper panel) and intron 6 (right panel; lower panel) as a control (see Materials and Methods for primers). Quantitative analysis of PCR amplicon intensities is shown in the lower part of the upper gel. Input sample comprised 5\% of the total precipitated DNA.

siRNA was used as a control (Materials and Methods). The reduction in the cellular concentration of Elk-1 was determined by Western blotting (Fig. 5C, left panel). ChIP analysis indicated that in the absence of Elk-1 protein the $h S l u 7$ promoter was not precipitated (Fig. 5C, right panel). To confirm that Elk-1 indeed repressed endogenous hSlu 7 expression, RT-PCR was used to determine the effect of knockdown of Elk-1 on the endogenous hSlu7 mRNA, Elk-1 mRNA, and on 18S rRNA expression. Reduction in Elk-1 levels caused a 3.5-fold induction of endogenous hSlu7 (Fig. 5D, left graph), while Elk-1 mRNA expression was reduced $>4$-fold (Fig. 5D, middle graph). No significant change was observed in $18 \mathrm{~S}$ rRNA expression (Fig. 5D, right graph). These results support the idea that hSlu7 expression is tightly regulated by Elk-1 and also suggests a physiological role of Elk-1 in downregulation of hSlu7 expression.

\section{The effects of Sp1 and Elk-1 on hSlu7 affect alternative splicing}

To examine if the effects of Sp1 and Elk1 on the transcription of $h S l u 7$ translate into affects on alternative splicing, we reduced the cellular concentrations of Spl and Elk-1 using RNA interference and examined the effects on alternative splicing. We previously showed that the nuclear concentration of hSlu7 affects alternative splicing of exon 8 of the $A D A R 10$ mini-gene and of exon 4 of DDO gene (Shomron et al. 2004, 2005). Figure 6 shows that treatment of cells with a short hairpin RNA (shRNA) specific for Sp1 gene reduced Sp1 and hSlu7 protein levels significantly and also reduced inclusion of exon 8 of $A D A R 10$ mini-gene (Fig. 6A, panel ii; Fig. 6B, panel i; cf. lanes 1 and 2 in all panels). To ensure specificity, the shRNA-Sp1 treated cells were cotransfected with Sp1 cDNA containing a silent mutation that prevents shRNA-directed degradation (see Materials and Methods) or an empty control pcDNA4 construct (Fig. 6A,B lanes 3,4, respectively). The silent Sp1 mutant restored both $\mathrm{Sp} 1$ and hSlu7 expression levels (Fig. 6A, lanes $3,4)$ and also restore exon 8 inclusion (Fig. 6B, lanes 3,4). The siRNA treatment did not affect the transcription of ADAR2 (data not shown). This indicates that the reduction in the inclusion of exon 8 after knocking down Sp1 did not derive from a decrease in the steady-state expression of the reporter construct. Also, Elk-1 siRNA treatment reduced Elk-1 protein concentration and thus enhanced the inclusion level of exon 4 of the $D D O$ gene (Fig. 5D,E, respectively). These results suggest that the cellular concentration of the transcription factors that regulate $h S l u 7$ transcription affects the level of exon inclusion or skipping in alternative splicing of specific exons. We demonstrated that two different transcription factors cause opposite effects on two different splicing events through regulation of hSlu7 


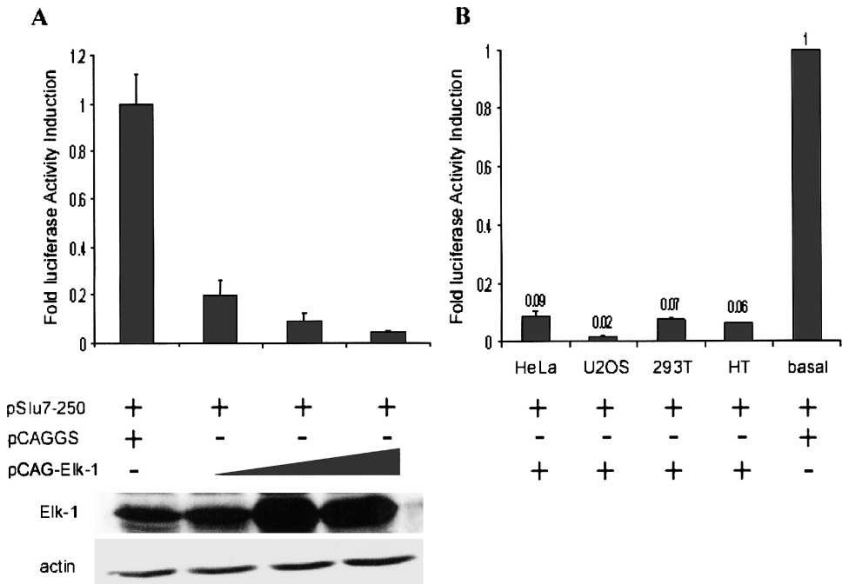

FIGURE 4. Repression of $h S l u 7$ promoter activity by Elk-1. (A) 293T cells were cotransfected with $250 \mathrm{ng}$ of reporter construct (pSlu7-luc) together with $100 \mathrm{ng}, 250 \mathrm{ng}$, or $500 \mathrm{ng}$ of either the expression plasmid pCAG-Elk-1 or the corresponding pCAGGS empty control vector. The fold induction represents the fold increase in luciferase activity $48 \mathrm{~h}$ post-transfection relative to that obtained following cotransfection of the reporter construct with a control vector (pCAGGS). Western blotting of 293T transfected cells with either anti-Elk-1 or anti-actin antibodies are also shown (bottom panels). (B) Elk-1-mediated repression of the $h$ Slu7 promoter occurred in several cell lines. Cell lines (HeLa, U20S, 293T, and HT1080) were cotransfected with $250 \mathrm{ng}$ of reporter construct (pSlu7-luc) together with $250 \mathrm{ng}$ of either the expression plasmid pCAG-Elk-1 or the corresponding pCAGGS empty control vector. Results are represented as the mean of at least three independent experiments (standard errors bars are shown; $n=3$; $P$-values represent $T$-test for each DNA dose group: $0.0016,0.00036$, and 0.00031 for $100 \mathrm{ng}, 250 \mathrm{ng}$, and $500 \mathrm{ng}$, respectively).

expression. We cannot exclude the possibility that the cellular concentrations of Sp1 and Elk-1 also affect transcription of other splicing factors involved in alternative splicing regulation of those exons. However, the splicing of the two genes analyzed was previously shown to be affected directly by the cellular concentration of hSlu7 (Shomron et al. 2004, 2005).

\section{DISCUSSION}

Previously, it was reported that the splicing factor hSlu7, a protein involved in the fidelity of the second step of splicing, is not required for cell viability but that the nuclear concentration of the protein regulates alternative splicing of certain genes (Shomron et al. 2004, 2005). This raised the question of whether $S l u 7$ expression is regulated among tissues. In this study, we demonstrated that Slu7 is differentially expressed among various tissues and cell lines. Moreover, Slu7 has unique patterns of expression within complex adult tissues and developing embryos, such as eye and pancreas. We also demonstrated that $h S l u 7$ transcription is regulated by at least two transcription factors, Sp1 and Elk-1, which might explain its differential expression.
It is intriguing that a splicing factor, one component of a megacomplex, has such a sophisticated mechanism for transcription regulation. Although very little is known about transcription regulation of other splicing factors (for example, see Romanelli et al. 2005), regulation of transcription of other nonsplicing proteins has been characterized (see,

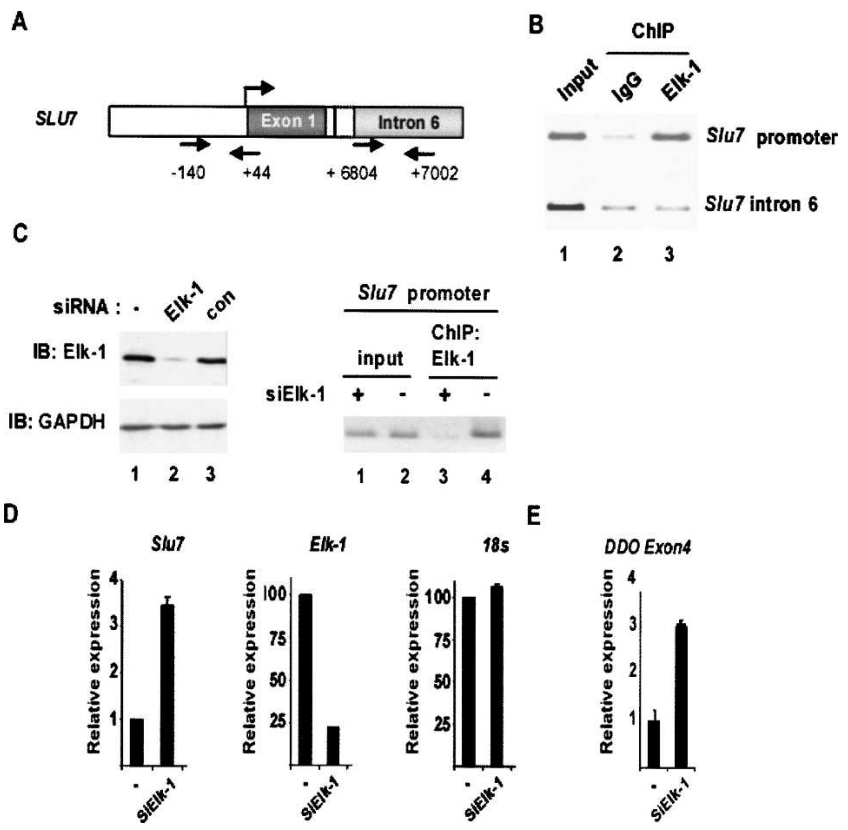

FIGURE 5. Elk-1 binds to the Slu7 promoter in vivo and knocking down Elk-1 induces $h S l u 7$ expression. (A) Schematic diagram of the Slu7 gene showing the location of the oligonucleotides used in the ChIP assay. (B) Elk-1 binds to hSlu7 promoter in vivo. HeLa cells were starved in serum-free DMEM for $48 \mathrm{~h}$ before harvesting. Sonicated chromatin was immunoprecipitated with either an anti-Elk-1 antibody or nonspecific IgG. PCR analysis of eluted DNA was performed using oligonucleotides specific for the Slu7 promoter (top panel) or Slu7 intronic sequence (lower panel). Five percent of input DNA is shown in lane 1 . The panels shown are inverted images of ethidium bromide-stained gels. Results shown are representative of four independent experiments. (C) Chromatin immunoprecipitation of Elk-1 bound to the Slu7 promoter in the presence or absence of a siRNA directed against Elk-1. HeLa cells were transfected with Elk-1 siRNA or a negative control siRNA $48 \mathrm{~h}$ before harvesting. Sonicated chromatin was immunoprecipitated with either an anti-Elk-1 antibody or nonspecific IgG. Right panel shows PCR analysis of eluted DNA using oligonucleotides specific for the Slu 7 promoter $(5 \%$ of input DNA is shown in lanes 1 and 2). Left panel shows a Western blot of HeLa cells treated in parallel. Results shown are representative of two independent experiments. (D) Knocking down Elk-1 levels induces expression of $S l u 7$ mRNA. HeLa cells were transfected with Elk-1 siRNA for $48 \mathrm{~h}$ before harvesting total RNA. RT-PCR was performed to detect endogenous Slu7 mRNA (left graph), Elk-1 mRNA (middle graph), and 18S rRNA expression (right graph). Results shown are representative of three independent experiments. (E) Knocking down Elk-1 levels results in increased inclusion of alternatively spliced exon 4 of the $D D O$ gene relative to cells treated with control siRNA. HeLa cells were transfected with Elk-1 siRNA for $48 \mathrm{~h}$ before harvesting total RNA. Real time RT-PCR was performed to detect endogenous DDO mRNA containing alternatively spliced exon 4. Results shown are representative of three independent experiments. 

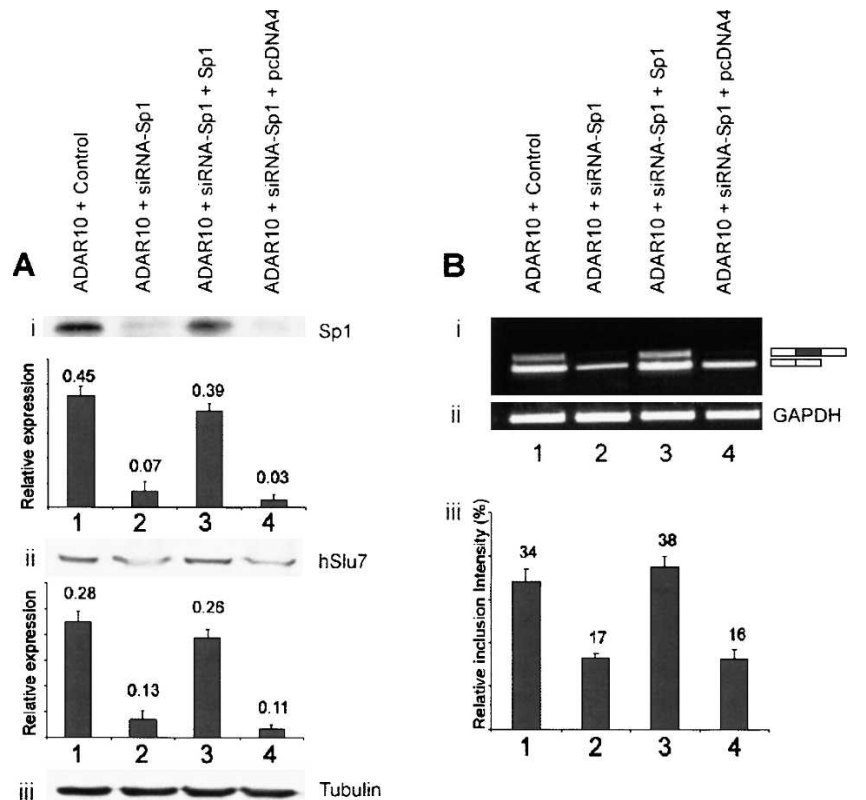

FIGURE 6. Knocking down Sp1 represses $h S l u 7$ expression and thus affects alternative splicing. $(A, B)$ 293T cells were transfected with ADAR10 mini-gene and with control shRNA expressing pSUPER retro (lane 1), shRNA targeting Sp1 (lane 2), or shRNA targeting Sp1 and also Sp1 expression vector containing a silent mutation that eliminates the shRNA activity (marked ${ }^{*} \mathrm{Sp} 1$, lane 3 ) or a control empty pcDNA4 vector (lane 4). The cells were incubated for $72 \mathrm{~h}$ before harvesting and analysis of total protein (panel $A, i, i i, i i i)$ or RNA (panel $B$ ). Samples were analyzed by Western blot with anti-Sp1, anti-tubulin antibodies (panel $A, i, i i i$, respectively), or anti-hSlu7 (panel $A$, ii). Band intensities were normalized to tubulin and quantitative analysis of both Sp1 and hSlu7 are shown at the bottom of each blot. Experiments were repeated three times in duplicate (error bar are shown). The two mRNA products and the control GAPDH mRNA are indicated (panel $B, i, i i$, respectively). Quantitative analysis of the inclusion levels of exon 8 of the ADAR10 for each experiment is shown (panel $B$, iii, in percentages). Experiments were repeated three times in duplicate (error bars are shown).

for example, Elkon et al. 2005) and exhibits patterns similar to the one described here. In addition, regulation of individual protein components of other large complexes, such as the DNA repair complex, is similar (Iwanaga et al. 2004). The results described here add an additional fascinating dimension to spliceosome assembly, namely, the timely expression of each component dictates the interplay with other proteins and ultimately dictates protein expression from specific genes. We cannot rule out that $S l u 7$ has roles in processes independent of its involvement with the spliceosome. Finally, Slu7 transcriptional regulation is another layer in the finely tuned regulation already described in our previous study involving binding of zinc to protein (Shomron et al. 2004).

Our results indicate that there are cells and tissues that lack or express negligible levels of Slu7. Wide-scale studies of splicing complexes revealed that some spliceosomal complexes did not contain Slu7 (for reviews, see Will and
Luhrmann 1997; Zhou et al. 2002; Jurica and Moore 2003; Deckert et al. 2006). Chau and Reed (1999a,b) have isolated a spliceosomal complex lacking $h S l u 7$ that loosely holds the free exon 1 (after the first step of mRNA splicing). The absence of $h \operatorname{Slu} 7$ causes aberrant attachment on different 3'ss-AGs. The complex interplay among splicing factors during spliceosome assembly is demonstrated by a number of results. The requirement of certain splicing factors for specific steps of splicing can be compensated by other factors (Chen et al. 2001; Kistler and Guthrie 2001). For example, mammalian UAP56 is required for prespliceosome formation. In the absence of the $M u d 2$ gene (yeast homolog for U2AF65), which interacts with SUB2 (yeast UAP56 homolog), SUB2 functionality becomes dispensable (Kistler and Guthrie 2001). In other cases, Prp28, a DEADbox protein, is required to promote the exchange of $\mathrm{U} 1$ for U6 at the 5'ss, but becomes dispensable after knockout of the U1C snRNP protein, which stabilizes the U1-5'ss interaction (Chen et al. 2001). Sub2 and $\operatorname{Prp} 28$ may have roles in splicing regulation and fidelity maintenance (Kistler and Guthrie 2001). Redundancy of Slu7 can bypass the need for another second-step splicing factor, $\operatorname{Prp18}$, in vitro (Zhang and Schwer 1997).

It is also worth noting that most of the research on splicing assembly and factor requirements has been conducted in vitro and/or in specific spliceosomal complexes (for example, Adeno ML and $\beta$-globin driven transcripts incubated in HeLa nuclear extract). It may be that the essential functions attributed to $h S l u 7$ are restricted to those conditions. For example, knocking down specific splicing factors in mouse revealed tissue-specific alternative splicing abnormalities and functionality (Ladd et al. 2005; Ule et al. 2005). The tight regulation on the hSlu7 promoter implies that the essential function of this protein might be restricted to certain cells/tissues or stages of embryonic differentiation. Although dispensable in cultured cells, Slu7 is likely to be essential in the context of a whole organism. For instance, $S p 1$ null/null mouse embryos die at $10 \mathrm{~d}$ of gestation (Marin et al. 1997; Pore et al. 2004). Redundancy of a related transcription factor, $S p 3$, may compensate for Sp1 absence (Bouwman et al. 2000).

We also suggest that the Slu7 promoter underwent changes throughout evolution. These changes may have served as a mechanism to shape Slu7's unique pattern of expression. We show here possible mechanisms for up- and down-regulation of $h S l u 7$ expression. Sp1 binds to the $h S l u 7$ promoter in vivo and up-regulates $S l u 7$ promoter activity in a dose-dependent manner. Depletion of this transcription factor was also shown to repress $h S l u 7$ expression. Sp1 recognizes GC-rich promoter elements, and, although it was reported to be ubiquitously expressed, it is also found to regulate many tissue-specifically expressed genes, viral genes, and cell-cycle-regulated genes (Bouwman and Philipsen 2002). Sp1 expression is variable in adult and developing embryonic tissues (Saffer et al. 1991; Nakamura et al. 2005). 
These observations imply that $\mathrm{Sp} 1$ might have a role in supporting $h S l u 7$ expression in a cell-type-specific manner.

Elk-1 repressed transcription from the $h S l u 7$ promoter and bound to the hSlu7 promoter in vivo. Moreover, siRNA-induced reduction of Elk-1 increased endogenous hSlu7 expression, suggesting that the Slu7 promoter is down-regulated by Elk-1. Elk-1-mediated repression was shown to be dose dependent in several cell lines. However, Elk-1-mediated repression of hSlu7 transcription was not completely abolished even after deletion of all five potential Elk-1 sites (data not shown). We also did not detect any potential serum response elements (SREs) in the promoter (these elements are required for SRF-dependent Elk-1 DNA binding). The repressive effects of Elk-1 are consistent with previous observations that Elk-1 associates with repressive complexes (Yang et al. 2001; Yang and Sharrocks 2004). The exact repression mechanism remains to be elucidated.

Gene expression profiles from microarray data sets revealed that in the PC3 prostate cell line there is an extremely low expression level of $\mathrm{Sp} 1$ (GEO accession GDS1736), whereas Elk-1 is expressed. This further corroborates results from our Spl siRNA assay that showed a significant reduction in $h S l u 7$ expression when Sp1 expression was reduced. We could not use this method to confirm the effects of Elk-1 expression levels on hSlu7 protein expression because no cell lines were found in which Elk-1 expression is very low or absent. We cannot rule out the possibility that other factors may contribute to the expression level of Slu7.

We have shown here that the temporal and spatial expression of the mammalian splicing factor Slu7 is elaborately regulated among tissues and during embryogenesis. The involvement of hSlu7 in regulation of alternative splicing of certain exons might indicate that $h S l u 7$ is essential for tissue- and differentiation-specific alternative splicing events.

\section{MATERIALS AND METHODS}

\section{Isolating the $5^{\prime}$ ends of human Slu 7 mRNA}

5'-RACE was performed according to the circular, or concatemeric, RACE methodology (Maruyama et al. 1995) in extract from 293T cells with a human Slu7 gene specific primer: $5^{\prime}$-TCCTCAGAGT TAACAATCTCCTTCC-3'. The first PCR primers were $5^{\prime}$-TGC TGGAGATAACTTTGTTAGGTACAC- $3^{\prime}$ and $5^{\prime}$-CTCATTTCTTT GGACCCCGATA-3'. The second, nested PCR primers were $5^{\prime}$ -

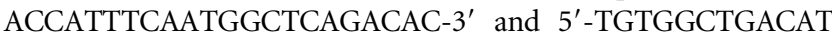
GGTTATCTGG-3'. The PCR product was eluted and purified following gel electrophoresis. After cloning into TOPO TA cloning vector (Invitrogen), 20 colonies were sequenced.

\section{Reporter and effector constructs}

The 5 '-flanking regions of the human Slu7 gene $[-184$ to +66 relative to TSS(1)] were amplified from genomic DNA and inserted upstream of the firefly luciferase gene in the reporter vector pGL3-basic (Promega) to create pSlu7-luc. Mutations were introduced using overlapping oligonucleotide primers containing the desired mutation. PCR was performed using the high-fidelity DNA polymerase UltraPfu (Stratagene); then reaction products were digested with DpnI restriction enzyme (New England Biolabs) for $1 \mathrm{~h}$ at $37^{\circ} \mathrm{C}$. A $5 \mu \mathrm{L}$ aliquot of the reaction was used to transform the Escherichia coli $\mathrm{DH} 5 \alpha$ strain, and DNA from positive colonies was extracted using a Mini-prep extraction kit (Qiagen). Primers were generated harboring the desired mutation (mutated nucleotide in bold) to abolish the GGAA core elements:

EBS_a_GG2TT_Fw 5'-GCCGGAATTAGGCGAAAAGCCTTAAGT AAACATTACGAGATTGG-3';

EBS_a_GG2TT_Rv 5'-CCAATCTCGTAATGTTTACTTAAGGCT TTTCGCCTAATTCCGGC-3';

EBS_b_GG2TT_Fw 5'-TACCGCAGTGGCCGCCTTAATTAGGC GAAAAGCC-3';

EBS_b_GG2TT_Rv 5'-GGCTTTTCGCCTAATTAAGGCGGCC ACTGCGGTA-3';

EBS_c_GG2TT_Fw 5'-CATGTGCCGGTCATCCTTAAGTTACC GCAGTGGC-3';

EBS_c_GG2TT_Rv 5'-GCCACTGCGGTAACTTAAGGATGACCG GCACATG-3';

EBS_d_AAA2CCT_Fw 5'-CCCGGCCCCGCCAGGCCTTTAGTG CGCATGTGC-3';

EBS_d_AAA2CCT_Rv 5'-GCACATGCGCACTAAAGGCCTGGC GGGGCCGGG-3';

EBS_e_CC2AA_Fw 5'-GAGTTCTCGCGTTTAACACGGCGCAG GAG-3';

EBS_e_CC2AA_Rv 5'-CTCCTGCGCCGTGTTAAACGCGAGAA CTC-3'.

The same primers were used to create all the combination mutants. Deletion mutants were created using two phosphorylated primers that flanked the desired regions followed by ligation of the clean PCR construct product. The pCAGGS (control vector) and pCAG-Elk-1 constructs were kindly provided by Dr. Hiroshi Kubota (Kyoto University) (Yamazaki et al. 2003). Sp1 mutated at the siRNA recognition site was cloned within the mammalian expression construct pcDNA4 (data not shown). Nucleotide sequences of the reporter and effector constructs were confirmed by sequencing.

\section{Cell line maintenance, transfection, and reporter gene assay}

HeLa, 293T, HT1080, and U2OS cells were grown on six-well plates and maintained in Dulbecco's modified Eagle's medium (DMEM) with $10 \%$ fetal calf serum (FCS), $0.29 \mathrm{mg} / \mathrm{mL}$ L-glutamine, $100 \mathrm{U} / \mathrm{mL}$ penicillin, $0.1 \mathrm{mg} / \mathrm{mL}$ streptomycin, and $1 \mathrm{U} / \mathrm{mL}$ nystatin at $37^{\circ} \mathrm{C}$ in a humidified atmosphere of $5 \% \mathrm{CO}_{2}$. Cells were grown for $24 \mathrm{~h}$ and then transfected with $250 \mathrm{ng}$ of reporter construct together with $250 \mathrm{ng}$ (or other dose as indicated) effector construct, including $20 \mathrm{ng}$ of internal control reporter vector (pRL-SV40; Promega) using FuGENE6 (Roche), as described in the manufacturer's protocol. Cell lysates were prepared and luciferase activities of transfected cells were determined using the dual luciferase assay system (Promega), according to the manufacturer's instructions, and the activity of firefly 
luciferase was normalized against that of the sea pansy enzyme (Renilla reniformis).

\section{RNA isolation, RT-PCR analysis, PCR, and quantitative RT-PCR}

Cells were grown in a 100-mm culture dish and were harvested $48 \mathrm{~h}$ after transfection. Total cytoplasmic RNA was extracted using TRI Reagent (Sigma), followed by treatment with $2 \mathrm{U}$ DNase (RNase-Free; Ambion). Tissue samples from three adult mice were homogenized in TRI reagent ( $1 \mathrm{~mL} / 30-100 \mathrm{mg}$ tissue). Firststrand oligo(dT)-primed cDNA synthesized with reverse transcriptase from avian myelobstosis virus (RT-AMV; Roche) from $1000 \mathrm{ng}$ of total RNA was amplified with High Fidelity Taq polymerase (Roche) and DDO, GAPDH, mSlu7, mPrp18, and Tubulin $\beta 5$ primers for 30 cycles, consisting of $94^{\circ} \mathrm{C}$ for $30 \mathrm{sec}$, $60-65^{\circ} \mathrm{C}$ for $45 \mathrm{sec}$, and $72^{\circ} \mathrm{C}$ for $1 \mathrm{~min}$. The products were separated in $2 \%$ agarose gel and confirmed by sequencing. For quantitative RT-PCR, total RNA was harvested using an RNeasy kit (Qiagen). RNA (40 ng) was used in a one-step RT-PCR reaction using Quantitect SYBR green reagent (Qiagen) and the following primers:

Slu7 forward, 5'-GTGGCCAAGAACATTTGGAT-3'; Slu 7 reverse, 5'-CATCGGCCTTCTTTCCAGTA-3'; Elk-1 forward, 5'-GGTGGTGAATTCAAGCTGGT-3'; Elk-1 reverse, 5'-ATTTGGCATGGTGGAGGTAA-3'; $18 \mathrm{~S}$ forward, 5'-TCAAGAACGAAAGTCGGAGGTT-3'; $18 \mathrm{~S}$ reverse, 5'-GGACATCTAAGGGCATCACAG-3'.

\section{Computational analyses}

The hSlu7 promoter sequence was scanned for binding sites for transcription factors using the following programs: TRANSPLORER (http://www.developmentontheedge.com/transplorer. shtml); Genomatix (http://www.genomatix.de/); NCITE (http:// www.softberry.com/berry.phtml); Signal Scan (http://bimas.dcrt. nih.gov/molbio/signal/); and TFSEARCH (http://molsun1.cbrc. aist.go.jp/research/db/TFSEARCH.html). Multiple alignment of the $h$ Slu 7 promoter region alignment was done using the ClustalW algorithm (http://www.ebi.ac.uk/clustalw/).

\section{In situ hybridization}

In situ hybridization analysis was performed as described by Yaron et al. (2006). For digoxigenin-labeled antisense RNAs, reverse transcription was performed on oligo(dT)-primed cDNA from mouse adult testis and brain tissues, and the resulting cDNA was used as a template for PCR. Standard PCR conditions were used with an annealing temperature of $68^{\circ} \mathrm{C}$ for 31 cycles. The PCR primers were mSlu7_973_F, 5'-GCTCAAACACAACTG TTTGCTTGG-3' and mSlu7_3UTR_R, 5'-TAATACGACTCAC TATAGGGCAGAGGACTGACGGCATGTACAT- $3^{\prime}$. For the sense negative control $m S l u 7$ probes, the same primers were used except that the T7 promoter tag was switched from the reverse to the forward primer. The resulting 1364-bp PCR products were analyzed and extracted from a $1 \%$ agarose gel, and the purified PCR products, including a 5'-T7 minimal promoter tag, were used to create the related digoxigenin-labeled antisense in vitro using DIG RNA labeling mix (Roche). The $S p 1$ probes and primers were used as reported before (Gray et al. 2004; Nakamura et al. 2005).

\section{RNA interference}

HeLa cells were transfected with $70 \mathrm{nM}$ Elk-1 siRNA (Dharmacon) or nontargeting control siRNA (Santa Cruz Biotechnology) using oligofectamine (Invitrogen) according to the manufacturer's protocol. HEK 293T cells were transfected with pSUPER.retro (Oligoengine) $S p 1$, and GFP control vectors expressing short hairpin (shRNA) against $S p 1$ corresponding to cDNA position 396 using fugene6 transfection reagent (Roche). For the Sp1 rescue analysis cells were also cotransfected with pSUPER.retro $S p 1$ and with either rescue construct expression Sp1 (mutated at the siRNA recognition site) or an empty control vector (pcDNA4; Invitrogen). At $72 \mathrm{~h}$ post-transfection, cells were harvested for protein and RNA preparation. Primers for the real time RT-PCR of DDO were exon3_Fw, 5'-CATTCACACGCAGAAGCAGT-3', and DDO_exon4 Rv, 5'-GGGTTGTAAAAGCCTGACCA-3'. Primers for detection of the inclusion level of exon 8 of ADAR10 transcript were described before (Lev-Maor et al. 2003).

\section{Chromatin immunoprecipitation}

U2OS cells were transfected with HA-Sp1 (in pcDNA4) for the immunoprecipitation of exogenous hemagglutinin (HA) tagged $S p 1$ proteins and an empty pCDNA4 as a control and were grown for $48 \mathrm{~h}$. HeLa cells were untransfected (for the immunoprecipitation of endogenous Elk-1 proteins). Cells were then treated with $1 \%$ formaldehyde for $10 \mathrm{~min}$ at room temperature before quenching with $0.125 \mathrm{M}$ glycine for $5 \mathrm{~min}$. Cells were harvested in ice-cold PBS with complete protease inhibitors (Roche), washed sequentially with BufferI (10 mM HEPES at pH 6.5, $0.5 \mathrm{mM}$ EGTA, 10 mM EDTA, 0.25\% Triton X-100) and BufferII (10 mM HEPES at pH 6.5, $0.5 \mathrm{mM}$ EGTA, $1 \mathrm{mM}$ EDTA, $200 \mathrm{mM} \mathrm{NaCl}$ ), and then resuspended in SDS lysis buffer $(50 \mathrm{mM}$ Tris at $\mathrm{pH} 8.1$, $10 \mathrm{mM}$ EDTA, 1\% SDS). Lysates were sonicated on ice to yield 200-800-bp DNA fragments. One quarter of a 10-cm dish was used per IP, diluted $1 / 10$ in IP Dilution buffer (0.01\% SDS, $1.1 \%$ Triton X-100, 1.2 mM EDTA, $16.7 \mathrm{mM}$ Tris at $\mathrm{pH} 8.1,167 \mathrm{mM}$ $\mathrm{NaCl}$ ), and incubated overnight at $4^{\circ} \mathrm{C}$ with either $1 \mu \mathrm{g}$ of Elk-1 antibody (Santa Cruz Biotechnology) for Hela cells or anti HA F-7 (Santa Cruz Biotechnology) for U2OS cells or $1 \mu \mathrm{g}$ nonspecific IgG (Upstate Biotechnology) for both cell types. Immunocomplexes were precipitated by incubation for $30 \mathrm{~min}$ with protein A-conjugated magnetic beads (Dynal) that had been preblocked by incubation with $10 \mu \mathrm{g}$ salmon sperm DNA. Immunoprecipitates were washed sequentially with TSEI $(20 \mathrm{mM}$, Tris at $\mathrm{pH} 8.1,2 \mathrm{mM}$ EDTA, $150 \mathrm{mM} \mathrm{NaCl}, 1 \%$ Triton X-100, $0.1 \%$ SDS), TSEII (20 mM Tris at pH 8.1, 2 mM EDTA, $500 \mathrm{mM}$ $\mathrm{NaCl}, 1 \%$ Triton X-100, 0.1\% SDS), BufferIII (10 mM Tris at pH 8.1, $0.25 \mathrm{M} \mathrm{LiCl,} 1 \mathrm{mM}$ EDTA, 1\% NP40, 1\% DOC), and TE before eluting in $1 \% \mathrm{SDS} / 0.1 \mathrm{M} \mathrm{NaHCO}_{3}$. Cross-links were reversed by heating to $65^{\circ} \mathrm{C}$ overnight, then treating with proteinase $\mathrm{K}$ for $1 \mathrm{~h}$ at $45^{\circ} \mathrm{C}$. Chromatin was cleaned using QiaQuick PCR cleanup columns (Qiagen). PCR was performed using specific primers to the human Slu7 promoter $(-140$ to +44 , relative to TSS(1); forward, 5'-GCTAGAGTTCTCGCGTTTCC-3'; reverse, 5'-CCAAGTCCATCCGACAGAAT-3') or Slu7 intronic sequence (intron $6,+6804$ to +7002 relative to TSS(1); forward, 


\section{5' -TGCAGTCAGTTTGGGAACAA-3'; reverse, 5' -TTCCCTGTTC} CTGGACATTT-3').

\section{Western blotting}

Lysis buffer $(50 \mathrm{mM}$ Tris at $\mathrm{pH} 7.5,1 \% \mathrm{NP} 40,150 \mathrm{mM} \mathrm{NaCl}$, $0.1 \%$ SDS, $0.5 \%$ deoxycholic acid, protease inhibitor cocktail, and phosphatase inhibitor cocktails I and II; Sigma) was used for protein extraction. Lysates were cold centrifuged for $30 \mathrm{~min}$ at $14,000 \mathrm{rpm}$. Total protein concentrations were measured using BioRad Protein Assay (Bio-Rad). Proteins were separated in 10\% SDS-polyacrylamide gel electrophoresis (SDS-PAGE) and then electroblotted onto a Protran membrane (Schleicher and Schuell). The membranes were probed with either anti-Elk-1, anti-actin antibody (Santa Cruz Biotechnology), anti-hSlu7 (Shomron et al. 2004; Abnova), or anti-Sp1 (BL938, Bethyl Laboratories), and anti$\alpha$-tubulin (B512; Sigma) followed by the appropriate secondary antibody. Immunoblots were visualized by enhanced chemiluminescence (Lumi-Light Western Blotting Substrate; Roche) and exposure to X-ray film. For ChIP assay, Western blotting was performed using Supersignal West Dura Extended Duration Substrate (Pierce) and primary antibodies anti-Elk-1 (Santa Cruz Biotechnologies) and anti-GAPDH (Abcam). Data were visualized using Bio-Rad Fluor-S MultiImager and Quantity One software (Bio-Rad).

\section{Image processing and microscopy}

Acquisition of images and measurement of DNA intensity was performed using TINA, ImageJ, and analySIS software (Soft Imaging System). Most of the results represent values obtained from at least three separate experiments, and the results are average values. Fluorescent images were taken with a confocal laser-scanning system, consisting of an SLM 410 Zeiss confocal microscope with a $20 \times$ or $40 \times$ oil objective.

\section{SUPPLEMENTAL DATA}

Supplemental Material is available at http://www.tau.ac.il/ gilast/ sup_mat.htm.

\section{ACKNOWLEDGMENTS}

This work was supported by a grant from the Israel Science Foundation (1449/04 and 40/05), MOP Germany-Israel, GIF, ICA through the Ber-Lehmsdorf Memorial Fund, and TAU Cancer Center. N.S. is funded in part by EURASNET. The work of R.A.-P. was supported by the Israel Science Foundation, Glaucoma Research Foundation, and the AMN Foundation.

Received February 5, 2007; accepted July 31, 2007.

\section{REFERENCES}

Ast, G. 2004. How did alternative splicing evolve? Nat. Rev. Genet. 5: 773-782.

Black, D.L. 2003. Mechanisms of alternative pre-messenger RNA splicing. Annu. Rev. Biochem. 72: 291-336.

Bouwman, P. and Philipsen, S. 2002. Regulation of the activity of Sp1-related transcription factors. Mol. Cell. Endocrinol. 195: $27-38$.
Bouwman, P., Gollner, H., Elsasser, H.P., Eckhoff, G., Karis, A., Grosveld, F., Philipsen, S., and Suske, G. 2000. Transcription factor Sp3 is essential for post-natal survival and late tooth development. EMBO J. 19: 655-661.

Chen, J.Y., Stands, L., Staley, J.P., Jackups Jr., R.R., Latus, L.J., and Chang, T.H. 2001. Specific alterations of U1-C protein or U1 small nuclear RNA can eliminate the requirement of Prp28p, an essential DEAD box splicing factor. Mol. Cell 7: 227-232.

Chua, K. and Reed, R. 1999a. Human step II splicing factor hSlu7 functions in restructuring the spliceosome between the catalytic steps of splicing. Genes \& Dev. 13: 841-850.

Chua, K. and Reed, R. 1999b. The RNA splicing factor hSlu7 is required for correct 3' splice-site choice. Nature 402: 207-210.

Cooper, T.A. 2005. Alternative splicing regulation impacts heart development. Cell 120: 1-2.

Deckert, J., Hartmuth, K., Boehringer, D., Behzadnia, N., Will, C.L., Kastner, B., Stark, H., Urlaub, H., and Luhrmann, R. 2006. Protein composition and electron microscopy structure of affinity-purified human spliceosomal B complexes isolated under physiological conditions. Mol. Cell. Biol. 26: 5528-5543.

Elkon, R., Rashi-Elkeles, S., Lerenthal, Y., Linhart, C., Tenne, T., Amariglio, N., Rechavi, G., Shamir, R., and Shiloh, Y. 2005. Dissection of a DNA-damage-induced transcriptional network using a combination of microarrays, RNA interference and computational promoter analysis. Genome Biol. 6: R43.

Frank, D., Patterson, B., and Guthrie, C. 1992. Synthetic lethal mutations suggest interactions between U5 small nuclear RNA and four proteins required for the second step of splicing. Mol. Cell. Biol. 12: 5197-5205.

Graveley, B.R. 2001. Alternative splicing: Increasing diversity in the proteomic world. Trends Genet. 17: 100-107.

Gray, P.A., Fu, H., Luo, P., Zhao, Q., Yu, J., Ferrari, A., Tenzen, T., Yuk, D.I., Tsung, E.F., Cai, Z., et al. 2004. Mouse brain organization revealed through direct genome-scale TF expression analysis. Science 306: 2255-2257.

Guil, S., Long, J.C., and Caceres, J.F. 2006. hnRNP A1 relocalization to the stress granules reflects a role in the stress response. Mol. Cell. Biol. 26: $5744-5758$.

Hanamura, A., Caceres, J.F., Mayeda, A., Franza Jr., B.R., and Krainer, A.R. 1998. Regulated tissue-specific expression of antagonistic pre-mRNA splicing factors. RNA 4: 430-444.

Hsu, T., Trojanowska, M., and Watson, D.K. 2004. Ets proteins in biological control and cancer. J. Cell. Biochem. 91: 896-903.

Iwanaga, R., Komori, H., and Ohtani, K. 2004. Differential regulation of expression of the mammalian DNA repair genes by growth stimulation. Oncogene 23: 8581-8590.

Jurica, M.S. and Moore, M.J. 2003. Pre-mRNA splicing: Awash in a sea of proteins. Mol. Cell 12: 5-14.

Kistler, A.L. and Guthrie, C. 2001. Deletion of MUD2, the yeast homolog of U2AF65, can bypass the requirement for sub2, an essential spliceosomal ATPase. Genes \& Dev. 15: 42-49.

Ladd, A.N., Taffet, G., Hartley, C., Kearney, D.L., and Cooper, T.A. 2005. Cardiac tissue-specific repression of CELF activity disrupts alternative splicing and causes cardiomyopathy. Mol. Cell. Biol. 25: 6267-6278.

Lander, E.S., Linton, L.M., Birren, B., Nusbaum, C., Zody, M.C., Baldwin, J., Devon, K., Dewar, K., Doyle, M., FitzHugh, W., et al. 2001. Initial sequencing and analysis of the human genome. Nature 409: 860-921.

Lev-Maor, G., Sorek, R., Shomron, N., and Ast, G. 2003. The birth of an alternatively spliced exon: $3^{\prime}$ splice-site selection in Alu exons. Science 300: 1288-1291.

Marin, M., Karis, A., Visser, P., Grosveld, F., and Philipsen, S. 1997. Transcription factor $\mathrm{Sp} 1$ is essential for early embryonic development but dispensable for cell growth and differentiation. Cell 89: 619-628.

Maruyama, I.N., Rakow, T.L., and Maruyama, H.I. 1995. cRACE: A simple method for identification of the $5^{\prime}$ end of mRNAs. Nucleic Acids Res. 23: 3796-3797. doi: 10.1093/nar/23.18.3796. 
Nakamura, H., Ueda, J., Sugar, J., and Yue, B.Y. 2005. Developmentally regulated expression of $\mathrm{Sp} 1$ in the mouse cornea. Invest. Ophthalmol. Vis. Sci. 46: 4092-4096.

Pelisch, F., Blaustein, M., Kornblihtt, A.R., and Srebrow, A. 2005. Cross-talk between signaling pathways regulates alternative splicing: A novel role for JNK. J. Biol. Chem. 280: 25461-25469.

Philips, A.V. and Cooper, T.A. 2000. RNA processing and human disease. Cell. Mol. Life Sci. 57: 235-249.

Pore, N., Liu, S., Shu, H.K., Li, B., Haas-Kogan, D., Stokoe, D., Milanini-Mongiat, J., Pages, G., O'Rourke, D.M., Bernhard, E., et al. 2004. Sp1 is involved in Akt-mediated induction of VEGF expression through an HIF-1-independent mechanism. Mol. Biol. Cell 15: 4841-4853.

Romanelli, M.G., Lorenzi, P., and Morandi, C. 2005. Identification and analysis of the human neural polypyrimidine tract binding protein (nPTB) gene promoter region. Gene 356: 11-18.

Saffer, J.D., Jackson, S.P., and Annarella, M.B. 1991. Developmental expression of Sp1 in the mouse. Mol. Cell. Biol. 11: 2189-2199.

Sgouras, D.N., Athanasiou, M.A., Beal Jr., G.J., Fisher, R.J., Blair, D.G., and Mavrothalassitis, G.J. 1995. ERF: An ETS domain protein with strong transcriptional repressor activity, can suppress ets-associated tumorigenesis and is regulated by phosphorylation during cell cycle and mitogenic stimulation. EMBO J. 14: 47814793.

Sharrocks, A.D. 2001. The ETS-domain transcription factor family. Nat. Rev. Mol. Cell Biol. 2: 827-837.

Shomron, N., Reznik, M., and Ast, G. 2004. Splicing factor hSlu7 contains a unique functional domain required to retain the protein within the nucleus. Mol. Biol. Cell 15: 3782-3795.

Shomron, N., Alberstein, M., Reznik, M., and Ast, G. 2005. Stress alters the subcellular distribution of hSlu7 and thus modulates alternative splicing. J. Cell Sci. 118: 1151-1159.

Thompson, J.D., Higgins, D.G., and Gibson, T.J. 1994. CLUSTAL W: Improving the sensitivity of progressive multiple sequence alignment through sequence weighting, position-specific gap penalties and weight matrix choice. Nucleic Acids Res. 22: 4673-4680. doi: 10.1093/nar/22.22.4673.

Ule, J., Ule, A., Spencer, J., Williams, A., Hu, J.S., Cline, M., Wang, H., Clark, T., Fraser, C., Ruggiu, M., et al. 2005. Nova regulates brainspecific splicing to shape the synapse. Nat. Genet. 37: 844-852.

van der Houven van Oordt, W., Diaz-Meco, M.T., Lozano, J., Krainer, A.R., Moscat, J., and Caceres, J.F. 2000. The MKK(3/6)- p38-signaling cascade alters the subcellular distribution of hnRNP $\mathrm{A} 1$ and modulates alternative splicing regulation. J. Cell Biol. 149: 307-316.

Wang, Z. and Grabowski, P.J. 1996. Cell- and stage-specific splicing events resolved in specialized neurons of the rat cerebellum. RNA 2: 1241-1253.

Waterston, R.H., Lindblad-Toh, K., Birney, E., Rogers, J., Abril, J.F., Agarwal, P., Agarwala, R., Ainscough, R., Alexandersson, M., An, P., et al. 2002. Initial sequencing and comparative analysis of the mouse genome. Nature 420: 520-562.

Will, C.L. and Luhrmann, R. 1997. Protein functions in pre-mRNA splicing. Curr. Opin. Cell Biol. 9: 320-328.

Xing, Y. and Lee, C. 2006. Alternative splicing and RNA selection pressure-evolutionary consequences for eukaryotic genomes. Nat. Rev. Genet. 7: 499-509.

Yamazaki, Y., Kubota, H., Nozaki, M., and Nagata, K. 2003. Transcriptional regulation of the cytosolic chaperonin theta subunit gene, Cctq, by Ets domain transcription factors Elk-1, Sap-1a, and Net in the absence of serum response factor. J. Biol. Chem. 278: 30642-30651.

Yang, S.H. and Sharrocks, A.D. 2004. SUMO promotes HDACmediated transcriptional repression. Mol. Cell 13: 611-617.

Yang, S.H., Vickers, E., Brehm, A., Kouzarides, T., and Sharrocks, A.D. 2001. Temporal recruitment of the mSin3Ahistone deacetylase corepressor complex to the ETS domain transcription factor Elk-1. Mol. Cell. Biol. 21: 2802-2814.

Yaron, O., Farhy, C., Marquardt, T., Applebury, M., and AsheryPadan, R. 2006. Notch1 functions to suppress cone-photoreceptor fate specification in the developing mouse retina. Development 133: 1367-1378.

Yeo, G., Holste, D., Kreiman, G., and Burge, C.B. 2004. Variation in alternative splicing across human tissues. Genome Biol. 5: R74.

Zhang, X. and Schwer, B. 1997. Functional and physical interaction between the yeast splicing factors Slu7 and Prp18. Nucleic Acids Res. 25: 2146-2152. doi: 10.1093/nar/25.11.2146.

Zhang, Q.S., Manche, L., Xu, R.M., and Krainer, A.R. 2006. hnRNP A1 associates with telomere ends and stimulates telomerase activity. RNA 12: 1116-1128.

Zhou, Z., Licklider, L.J., Gygi, S.P., and Reed, R. 2002. Comprehensive proteomic analysis of the human spliceosome. Nature 419: 182-185. 

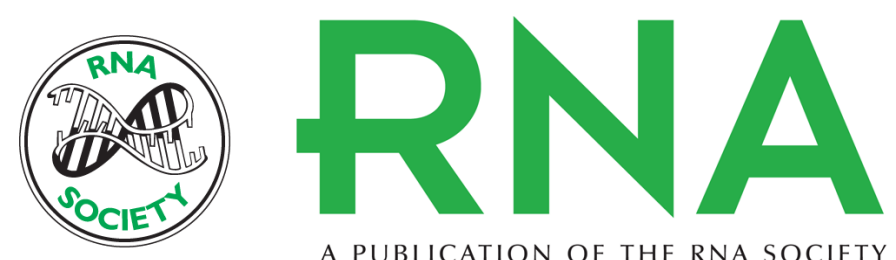

A PUBLICATION OF THE RNA SOCIETY

\section{Regulation of transcription of the RNA splicing factor $h S / u 7$ by Elk-1 and Sp1 affects alternative splicing}

Moti Alberstein, Maayan Amit, Keren Vaknin, et al.

RNA 2007 13: 1988-1999 originally published online September 5, 2007

Access the most recent version at doi:10.1261/rna.492907

References This article cites 49 articles, 22 of which can be accessed free at:

http://rnajournal.cshlp.org/content/13/11/1988.full.html\#ref-list-1

License

Email Alerting Receive free email alerts when new articles cite this article - sign up in the box at the Service top right corner of the article or click here.

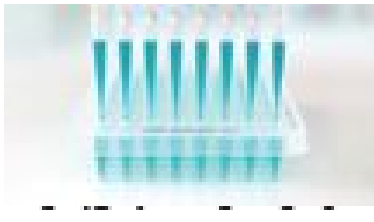

Providing Precise Solutions for your research.

To subscribe to RNA go to:

http://rnajournal.cshlp.org/subscriptions 